\title{
Helium isotopes in 79 A.D. Mt.Somma-Vesuvius paleofluids
}

\author{
G. MAGRO ${ }^{1}$, F. GHERARdI ${ }^{1 *}$ \\ ${ }^{1}$ Consiglio Nazionale delle Ricerche (CNR) - Istituto di \\ Geoscienze e Georisorse (IGG), Pisa, 56124, Italy \\ (g.magro@igg.cnr.it; "correspondence: \\ f.gherardi@igg.cnr.it)
}

Mt.Somma-Vesuvius is a moderate-sized stratovolcano (1132 $\mathrm{m}$ above sea level) located in a densely populated area close to the city of Naples, in Southern Italy. This area has experienced intense volcanism during Quaternary, and is considered one of volcanic areas at highest risk in the world. For this reason, over the past decades, a large number of studies has advanced knowledge on the physical and geochemical evolution of the volcano.

In order to get some additional insights on the mechanisms that control magma evolution at Mt.SommaVesuvius, we investigated helium isotopes on melt and fluid inclusions from pyroxene, olivine and sanidine crystals. We focused on products of the 79 A.D. plinian eruption, and we investigated rocks representative of different portions of the magma chamber. They range from early-erupted phonolotic white pumice to late-erupted, tephri-ponolitic grey pumice, and also include cumulites, metasomatized cumulites, and syenites.

We measured ${ }^{3} \mathrm{He} /{ }^{4} \mathrm{He}$ ratios between 1.5 to $2.7 \mathrm{Ra}$. Highest ratios were observed in cumulites, representative of the roof and the walls of the magma chamber. Lowest values occurred in sanidines representative of the magma-skarn interface. Noteworthy, the highest measured values of the 79 A.D. paleofluids were comparable with both lavas and pyroclastites emitted under open-conduit conditions during the 1631-1944 A.D. period, and present-day fumarolic discharges.

Ageing and interaction with crustal rocks emerged as an effective mechanisms that lowered the ${ }^{3} \mathrm{He} /{ }^{4} \mathrm{He}$ ratio of the melt during its intra-crustal magma chamber stay. Higher ${ }^{3} \mathrm{He} /{ }^{4} \mathrm{He}$ ratios seemed to be associated with more dynamic conditions. Overall, He isotope data are consistent with a layered magma chamber model, were convective mixing is driven by the inflow of mafic magma pulses from the root of the system. 